Chimia 46 (1992) 215-217

(C) Neue Schweizerische Chemische Gesellschaft ISSN 0009-4293

\title{
Evanescent-Wave Spectroscopy on Bulk-Response Optode Membranes
}

René E. Dohner, Ursula E. Spichiger, and Wilhelm Simon*

Abstract. The absorbance of a solvent polymeric bulk optode membrane in contact with sapphire as a wave-guide is studied with the attenuated total reflection (ATR) technique. Utilizing thin $(\leq 1 \mu \mathrm{m})$ and, therefore, fast-responding membranes, high values of absorbance are obtained by multiple internal reflection (MIR). The approach has an advantage over conventional transmission studies in that the light beam does not pass through the sample solution. Sample-induced swelling of the membrane may, however, create problems.

\section{Introduction}

Recently, a quite generally applicable concept for sensing ions as well as certain neutral analytes by bulk optode membranes has been described [1-3]. It is fundamentally suitable for transmission and reflectance as well as luminescence measurements [1-3]. With only few exceptions, absorbance measurements have been carried out using conventional spectrophotometers [4-7] or photodiodes coated with such bulk optode membranes [8][9]. For practical applications, inaccuracies arising from sample-induced scattering and/or absorption changes in the transmission mode were compensated by referencing to a blank membrane [10-13]. Fluorescence studies on the same systems [14] and reflectance measurements on similar but not reusable reagent layers [15] have been described. Here, we report on a preliminary study of evanescent-wave spectroscopy (for further literature see [1620]) applied to $\mathrm{Ca}^{2+}$-selective optode membranes which were previously characterised in the transmission mode [7][11].

*Correspondence: Prof. Dr. W. Simon Swiss Federal Institute of Technology (ETH) Department of Organic Chemistry Universitätstrasse 16 $\mathrm{CH}-8092$ Zürich ethylhexyl) sebacate $\left(\mathrm{C}_{26} \mathrm{H}_{50} \mathrm{O}_{4}\right.$; DOS), and 75 mg of poly (vinyl chloride) (high molecular weight PVC), all Selectophore ${ }^{\circledR}$ from Fluka $A G$, Buchs, Switzerland.

A $0.2 \mathrm{ml}$ portion of this soln. was brought onto a rotating, dust-free sapphire plate (single parallel MIR crystal, $52 \mathrm{~mm} \times 10 \mathrm{~mm} \times 1 \mathrm{~mm}, 30$ internal reflections, angle of incidence $60^{\circ}$, refractive index 1.768 at $20^{\circ}$; Victor Kyburz $A G$, Safnern, Switzerland). This plate had been placed in a closed vessel saturated with $\mathrm{THF}$, which formed part of a spin-on device [21] (rotating frequency $800 \mathrm{rpm}$ ) allowing the preparation of membranes with controlled and reproducible thickness of $0.5-2 \mu \mathrm{m}$. After removing the sapphire plate with the optode membrane from the spin-on device, it was left at r.t. for some $h$ for further drying. The refractive index of the membrane was 1.474 as determined by an $A b b e$ refractometer (Carl Zeiss, Oberkochen, Württ., Germany) at $20^{\circ}$.

\subsection{Optical System}

Optical measurements were performed using a Fourier-transform microscopic spectrophotometer in the transmission mode (Hitachi model $U$ 6000 microscopic FT spectrophotometer, Hitachi Lid., Tokyo). The light beam, emitted from a 50 Whalogen lamp, was focussed via a collimator lens on the sapphire crystal at an angle of incidence of $60^{\circ}$ (see Fig. I). In the attenuated total reflectance (ATR) mode (evanescent-wave), the absorbance of the sapphire-supported membrane in contact with different sample solns. was studied by measuring the output of the light intensity with the above spectrophotometer. For that purpose, the membrane (provided with a Teflon ${ }^{(0)}$ spacer of $0.2 \mathrm{~mm}$ thickness) formed one wall of a thermostated $\left(25^{\circ}\right)$ flow-through cell of $36 \mu$ volume, through which the sample soln. was driven (see Fig. I) by a peristaltic pump $(11 \mathrm{ml} /$ h).

\subsection{Reagents}

Doubly quartz-distilled $\mathrm{H}_{2}$ Oand chemicals of p.a. grade were used throughout. $\mathrm{CaCl}_{2}$ solns. were prepared with a $\mathrm{NaOAc}$ buffer of $\mathrm{pH} 3.65$.

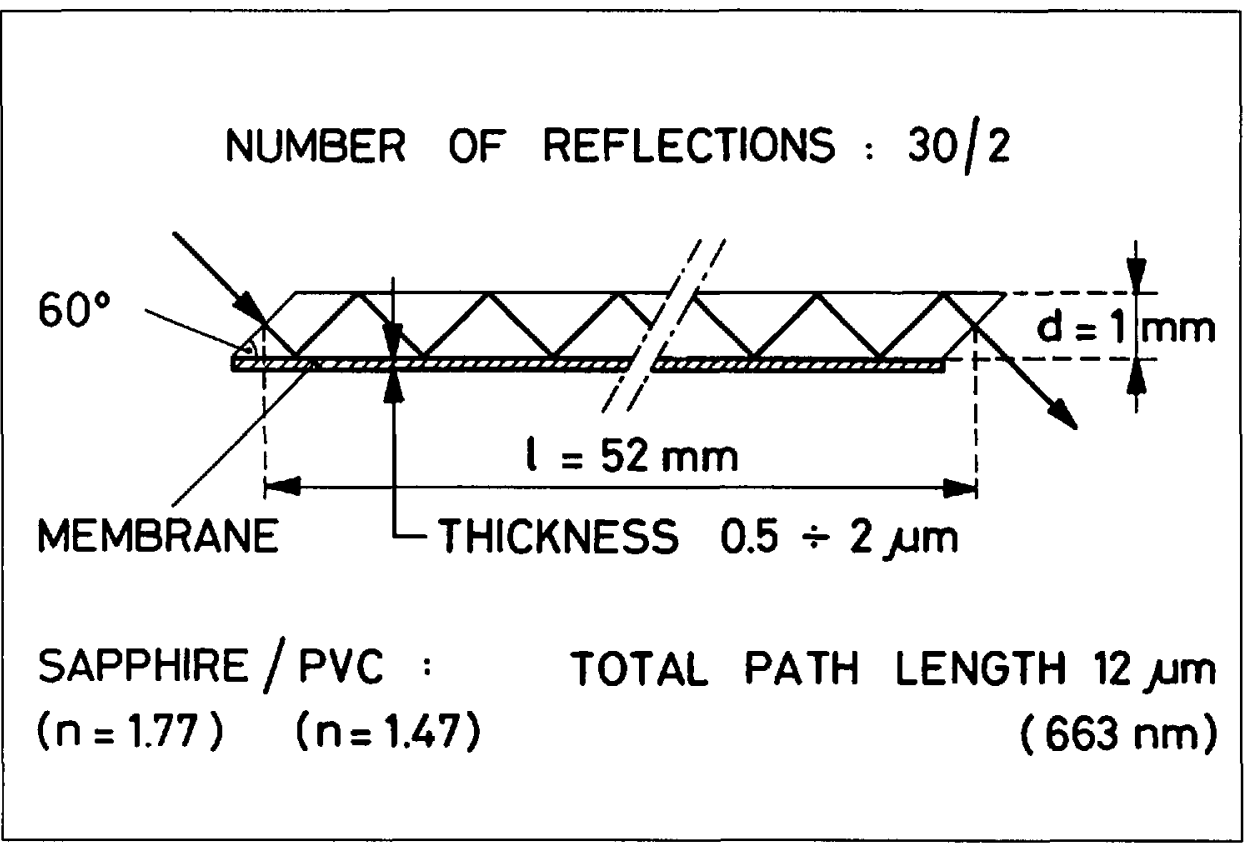

Fig. 1. Schematic diagram of sapphire wave-guide (ATR) in contact with an ion-selective PVC optode membrane 


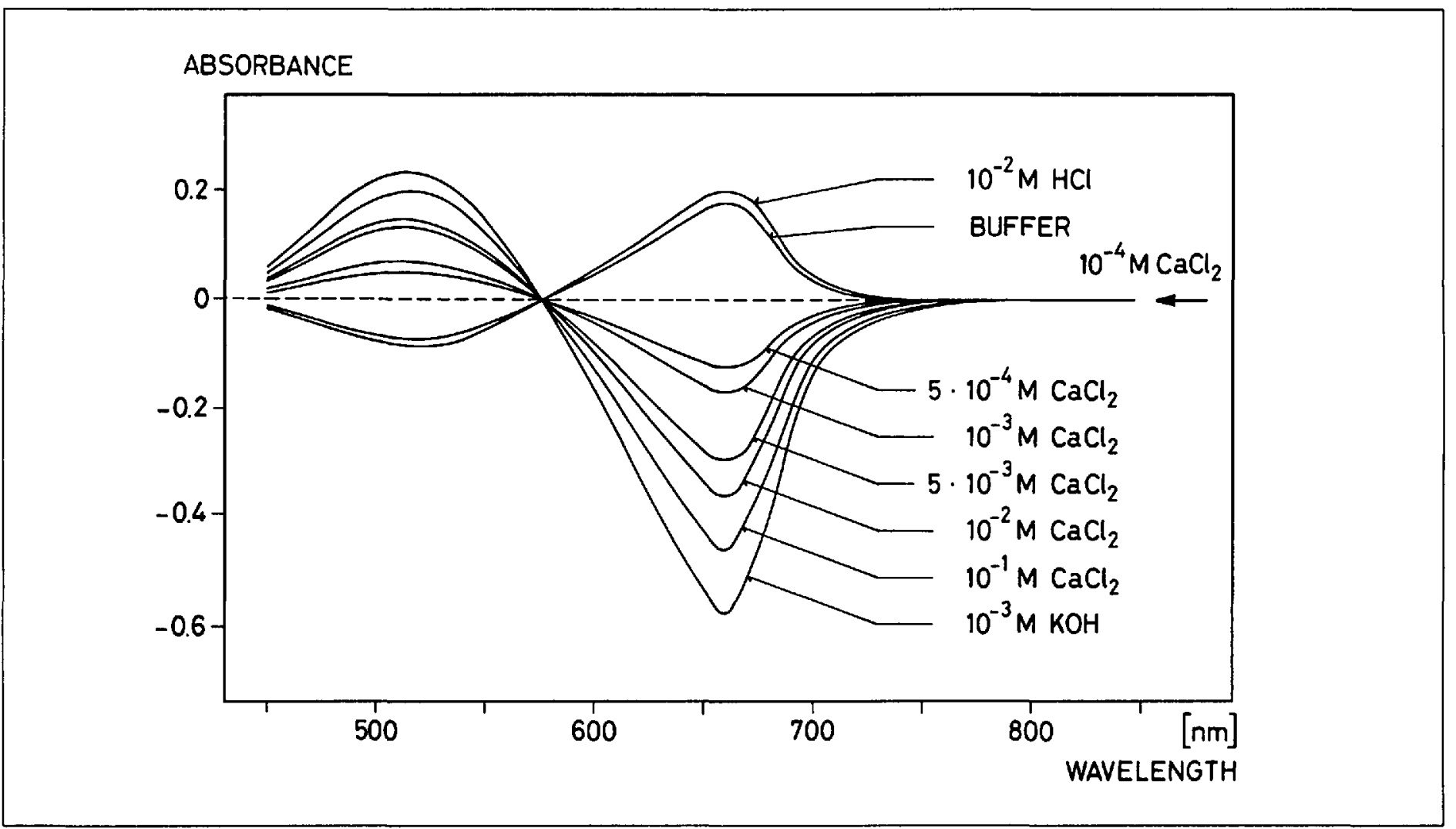

Fig. 2. Normalized evanescent-wave spectra taken in the ATR approach on a $\mathrm{Ca}^{2+}$-selective optode membrane in contact with different sample solutions (see Experimental)

Fig. 3. Experimental evanescent-wave response in comparison with computed curve (solid line). $1-\alpha$ : Degree of protonation.

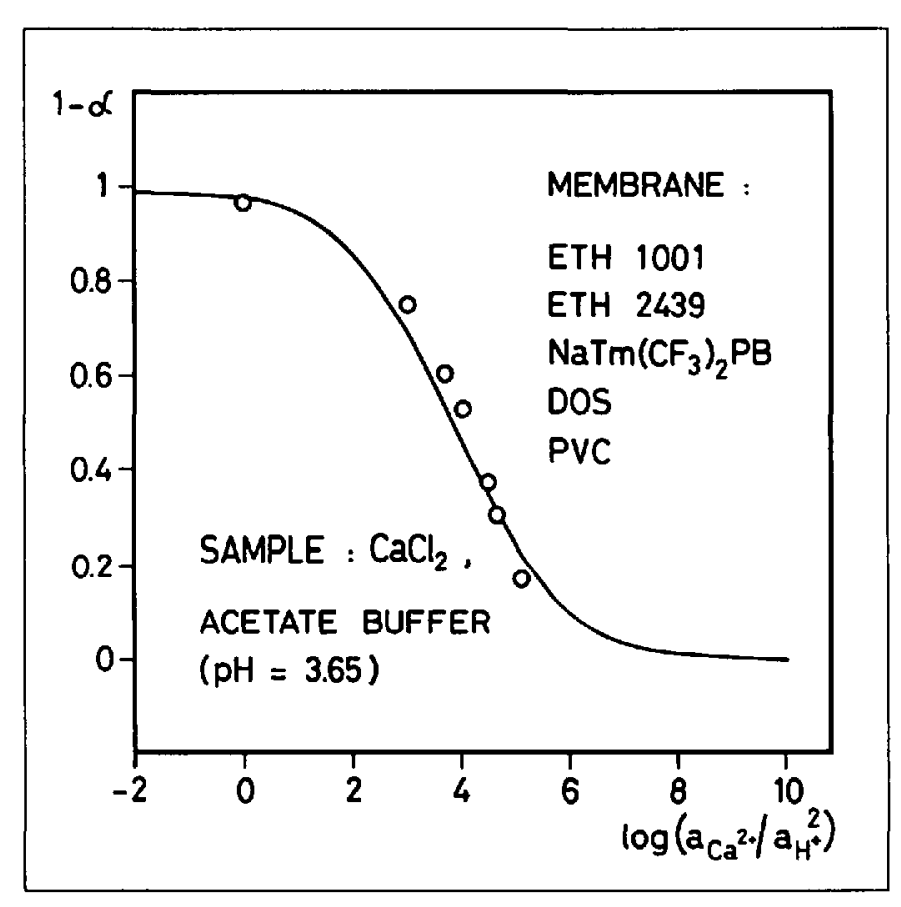

Such a bulk-response optode membrane, extracting analytes from the sample solution, was put in contact with a sapphire crystal acting as an optical waveguide (see Fig. I). For a light beam $(\lambda=$ $663 \mathrm{~nm})$ at an angle of incidence of $60^{\circ}$ and refractive indices of 1.768 and 1.474 for sapphire and PVC membrane, respectively (see Experimental), an effective path length of $831 \mathrm{~nm}$ (hypothetical thickness averaged for perpendicular and parallel polarized light) is calculated for each re- flectance [18-20]. A crystal of $52 \mathrm{~mm}$ length therefore provides an effective path length of 15 times $831 \mathrm{~nm} \cong 12 \mu \mathrm{m}$ (one side of sapphire plate; number of reflections: 30/2). With membranes of ca. $1 \mu \mathrm{m}$ thickness, membrane-inherent response times of $c a .1 \mathrm{~s}$ have been obtained [7]. The response time of a $12 \mu \mathrm{m}$ thick membrane in the transmission mode would be at least 100 times higher, although the absorbance observed in the ATR approach described here remains comparable. Therefore, thin membranes can be used in the MIR mode to produce sensors of fast response, simultaneously exhibiting high absorbances. Furthermore, in the evanescent-wave spectroscopy, the light beam does not pass through the sample solution if the membrane is sufficiently thick (in the present case: $\geq 253 \mathrm{~nm}$, penetration depth of the electromagnetic field vector in a bulk membrane phase [20]).

From measurements in the transmission mode on a DOS/PVC membrane containing the chromoionophore ETH 2439 , molar decimal absorption coefficients of $7.1 \cdot 10^{4} \mathrm{~mol}^{-1} \mathrm{~cm}^{-1}$ (at $656 \mathrm{~nm}$ ) and $3.2 \cdot 10^{4}$ $1 \mathrm{~mol}^{-1} \mathrm{~cm}^{-1}$ (at $512 \mathrm{~nm}$ ) were calculated for the absorption maxima of protonated and deprotonated form, respectively. Based on these values, such a membrane of only $1 \mu \mathrm{m}$ thickness should give an absorbance of ca. 0.15 .

Evanescent-wave spectra obtained with a Ca ${ }^{2+}$-selective optode membrane of similar thickness (see Experimental) in contact with different sample solutions are 
given in Fig. 2. They are normalized for $10^{-4} \mathrm{M} \mathrm{CaCl}_{2}$ solutions and the isosbestic point at $570 \mathrm{~nm}$. The absorbance difference between protonated (in $10^{-2} \mathrm{M} \mathrm{HCl}$ ) and deprotonated (in $10^{-3} \mathrm{M} \mathrm{KOH}$ ) form of the chromoionophore is 0.859 for the ATR system described here (Fig. 1), corresponding to 0.072 for a membrane of $c a .1 \mu \mathrm{m}$ thickness in the conventional transmission mode.

When plotting the degree of protonation, $1-\alpha$, of the chromoionophore against the ratio of activities, $\mathrm{a}_{\mathrm{Ca}_{2}+} / \mathrm{a}_{\mathrm{H}^{+}}$(for details, see [7][21]), the sigmoidal shape of the theoretically predicted response curve [1-3] is corroborated (Fig. 3), although the deviations of the experimental data points from the computed curve are larger than those observed in conventional absorption studies [4][7].

In contrast to transmission measurements, where a swelling of the membrane due to contact with different sample solutions does not cause problems, in the evanescent-wave approach a decrease in absorbance is expected with increasing membrane volume. Indeed, baseline shifts of up to $6 \%$ in absorbance can be observed when changing from $10^{-1}$ to $10^{-4} \mathrm{M} \mathrm{CaCl}_{2}$ sample solutions. In the conventional transmission mode, however, the corresponding shifts are well below $1 \%$.

At a sample flow rate of $11 \mathrm{ml} / \mathrm{h}\left(10^{-4}\right.$

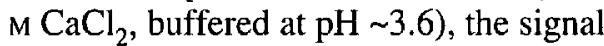
stability (at $663 \mathrm{~nm}$ ) for the system described here amounts to \pm 0.002 and \pm 0.005 in absorbance with and without optode membrane, respectively. The re- producibility of the signal is $1.6 \%$ (SD, $n=7$ ) when changing from $10^{-4}$ to $10^{-3} \mathrm{M}$ $\mathrm{CaCl}_{2}$ solutions, and the signal stability within $1 \mathrm{~h}$ is $0.8 \%$.

We thank Dr.K. Oishi and K. Matsui (NAKA Works, Instrument Division, Hitachi Ltd., Japan) for providing a Hitachi model $U-6000$ microscopic FT spectrophotometer as well as for valuable advice. We are also grateful to Prof. Dr. $U$. $P$. Fringeli (University of Vienna) for helpful discussions.

Received: March 9, 1992

[1] W. E. Morf, K. Seiler, B. Lehmann, Ch. Behringer, K. Hartman, W. Simon, Pure Appl. Chem. 1989, 61, 1613 .

[2] W. E. Morf, K. Seiler, B. Lehmann, Ch. Behringer, S. Tan, K. Hartman, P. R. Sørensen, W. Simon, in 'Ion-Selective Electrodes', Ed. E. Pungor, Pergamon Press, Oxford-New York; Akadémiai Kiadó, Budapest, 1989, Vol. 5, p. 115.

[3] W. E. Morf, K. Seiler, P. R. Sørensen, W. Simon, in 'Ion-Selective Electrodes', Ed. E. Pungor, Pergamon Press, Oxford-New York; Akadémiai Kiadó, Budapest, 1989, Vol. 5, p. 141 .

[4] W. Simon, W. E. Morf, K. Seiler, U. E. Spichiger-Keller, FreseniusJ. Anal.Chem. 1990, 337, 26.

[5] P. Holý, W. E. Morf, K. Seiler, W. Simon, J.-P. Vigneron, Helv. Chim. Acta 1990, 73, 1171.

[6] K. Seiler, W. E. Morf, B. Rusterholz, W. Simon, Anal. Sci. 1989, 5, 557.

[7] W. E. Morf, K. Seiler, B. Rusterholz, W. Simon, Anal. Chem. 1990, 62, 738.
[8] Ph. M.J.Périsset, P.C. Hauser, S.S.S.Tan, K. Seiler, W. E. Morf, W. Simon, Chimia $1989,43,10$.

[9] P.C. Hauser, Ph. M. J. Périsset, S. S.S.Tan, W. Simon, Anal. Chem. 1990, 62, 1919.

[10] K. Wang, K. Seiler, W. E. Morf, U. E. Spichiger, W. Simon, E. Lindner, E. Pungor, Anal. Sci. 1990, 6, 715.

[11] R. Eugster, K. Seiler, W.E. Morf, K. Wang, M. Csösz, B. Rusterholz, W. Simon, U. E. Spichiger, GIT Labor-Medizin 1991, 14, 352.

[12] S. S. S. Tan, P. C. Hauser, K. Wang, K. Fluri, K. Seiler, B. Rusterholz, G. Suter, M. Krüttli, U. E. Spichiger, W. Simon, Anal. Chim. Acta 1991, 255, 35.

[13] U. E. Spichiger, K. Seiler, K. Wang, G. Suter, W. E. Morf, W. Simon, Proc. SPIEInt. Soc. Opt. Eng. 1991, 1510, 118.

[14] H. He, G. Uray, O. S. Wolfbeis, Proc. SPIE-Int. Soc. Opt. Eng. 1991, 1510, 95.

[15] B. Walter, Anal. Chem. 1983, 55, 498A.

[16] R. A. Lieberman, in 'Fiber Optic Chemical Sensors and Biosensors', Ed. O. S. Wolfbeis, CRC Press, Boca Raton-Ann ArborBoston-London, 1991, Vol. I, p. 193.

[17] P. W. Bohn, Trends Anal. Chem. 1987, 6, 223.

[18] R. M. Sutherland, C. Dähne, in 'Biosensors, Fundamentals and Applications', Eds. A. P. F. Turner, I. Karube, and G. S. Wilson, Oxford University Press, Oxford-New York-Tokyo, 1987, p. 655.

[19] K. Nishizawa, in 'Chemical Sensor Technology', Ed. T. Seiyama, Kodansha Ltd., Tokyo; Elsevier, Amsterdam, 1988, Vol. I, p. 237.

[20] U.P. Fringeli, in 'Internal Reflection Spectroscopy: Theory and Application', Ed. F. M. Mirabella, Marcel Dekker Inc., New York, 1992, in press.

[21] K. Seiler, W. Simon, Anal. Chim. Acta 1992, in press. 